\title{
The blood level of transforming growth factor- $\beta$ rises in the early stages of acute protein and energy deficit in the weanling mouse
}

\author{
Jennifer M. Monk and Bill Woodward* \\ Department of Human Health and Nutritional Sciences, University of Guelph, Guelph, ON, Canada N1G 2W1
}

(Received 1 May 2009 - Revised 22 July 2009 - Accepted 16 September 2009 - First published online 27 November 2009)

Plasma transforming growth factor (TGF)- $\beta$ levels are high in the advanced stages of acute (wasting) pre-pubescent deficits of protein and energy. Consequently, this potently anti-inflammatory cytokine may help to sustain the depression of inflammatory immune competence in acute malnutrition. Our objective was to determine if plasma TGF- $\beta$ levels rise during the early stages of acute malnutrition and, secondarily, to confirm the elevation reported previously in advanced weight loss. In two experiments, male and female C57BL/6J mice, initially $19 \mathrm{~d}$ old, consumed ad libitum a complete purified diet (group C), or in restricted daily quantities (group R) or had free access to an isoenergetic low-protein diet (group LP). TGF- $\beta$ bioactivity in platelet-poor plasma was determined via inhibition of Mv1Lu mink lung cell proliferation after $3 \mathrm{~d}$ (Expt 1 , early stage) or $14 \mathrm{~d}$ (Expt 2, advanced stage) of dietary intervention. At $3 \mathrm{~d}$, mean plasma TGF- $\beta$ bioactivities were 802 (C), 2952 (R) and 4678 (LP) pg/ml, and after $14 \mathrm{~d}$ mean bioactivities were $1786(\mathrm{C}), 5360(\mathrm{R})$ and $5735(\mathrm{LP}) \mathrm{pg} / \mathrm{ml}$. At both time points, the malnourished groups differed from age-matched controls $(P \leq 0 \cdot 05)$. Thus, metabolically distinct weanling systems mimicking paediatric marasmus (group R) and kwashiorkor (group LP) exhibit an early rise in blood TGF- $\beta$ concentration, and this cytokine joins corticosterone and IL-10 as a third anti-inflammatory hormone temporally positioned to contribute to the initiation (and maintenance) of malnutrition-associated immune depression. This investigation contributes new insight into the active anti-inflammatory form of immune competence that appears to prevail in acute pre-pubescent malnutrition.

Cytokines: Mice: Protein-energy malnutrition: Transforming growth factor- $\beta$

A defining characteristic of acute (i.e. wasting) pre-pubescent protein and energy deficit is depressed inflammatory immune competence, although the aetiology of this aspect of malnutrition pathology is poorly understood ${ }^{(1)}$. A recent proposition suggests that this immunological phenomenon represents a regulated pathophysiology, controlled by hormones and cytokines, rather than a biologically trivial disintegrative loss of immunological control ${ }^{(1)}$. In this connection, murine models that closely mimic acute paediatric malnutrition exhibit elevations in blood levels of three potent anti-inflammatory mediators, namely corticosterone ${ }^{(2)}$, IL- $10^{(3)}$ and transforming growth factor (TGF)- $\beta^{(3)}$, in the most advanced stages of wasting pathology. Moreover, in the same pre-pubescent experimental systems, blood levels of both corticosterone ${ }^{(2)}$ and $\mathrm{IL}-10^{(4)}$ rise in the early stages of weight loss. Importantly, high blood levels of TGF- $\beta$ are also reported in the advanced stages of a completely different model of acutely protein-deficient weanling guinea pigs vaccinated with Mycobacterium tuberculosis ${ }^{(5)}$. Blood concentrations of hormones and cytokines represent spillover from the extravascular compartment and may be regarded as reflective, although probably not representative, of concentrations at extravascular sites of action ${ }^{(3,6)}$. High levels of glucocorticoids and IL-10, therefore, are positioned temporally to initiate depressed inflammatory capacity in the early stages of acute malnutrition, and a potent triad including the glucocorticoids, IL-10 and TGF- $\beta$ is likewise positioned to serve in a sustaining role. It is unknown whether TGF- $\beta$ might also contribute to the initiation of malnutrition-associated depression in inflammatory immune competence.

TGF- $\beta$ exerts potently anti-inflammatory and immune suppressive effects impacting cells of both the innate and adaptive arms of immune defence ${ }^{(7)}$, and this cytokine is regarded as a dominant peripheral mediator of anti-inflammatory selftolerance ${ }^{(8,9)}$. The objective of this investigation was to determine if the blood TGF- $\beta$ concentration rises during the early stages of acute pre-pubescent malnutrition in metabolically distinct murine models known to depress inflammatory immune competence ${ }^{(10-12)}$. Additionally, a confirmatory experiment was conducted assessing blood levels of TGF- $\beta$ in the advanced stages of acute weanling malnutrition.

\section{Materials and methods}

\section{Animals and facilities}

Male and female C57BL/6J mice were obtained from an in-house breeding colony. Caging and housing conditions were exactly as described previously ${ }^{(2,12)}$, and this investigation

Abbreviation: TGF, transforming growth factor.

*Corresponding author: Dr Bill Woodward, fax +1 519763 5902, email wwoodwar@uoguelph.ca 
was approved by the Animal Care Committee of the University of Guelph in accordance with the guidelines of the Canadian Council on Animal Care.

\section{Diets and feeding protocols}

At $18 \mathrm{~d}$ of age, the animals were weaned, individually housed and given free access for $1 \mathrm{~d}$ to a complete purified diet that is described elsewhere ${ }^{(13)}$. At $19 \mathrm{~d}$ of age, the mice were randomly allocated to one of three experimental groups. An age-matched control group was given ad libitum access to the aforementioned complete purified diet. An energyrestricted group consumed the complete diet in restricted daily quantities determined by calculations that relate ad libitum food intake ( $\mathrm{g}$ food/g body weight) to chronological age in the weanling mouse ${ }^{(12)}$. Finally, a low-protein group was given free access to a purified diet formulated to contain $0.6 \%$ crude protein by replacement of most of the nitrogen source of the complete diet by maize $\operatorname{starch}^{(10)}$. These malnutrition protocols reproduce the critical features of the paediatric human pathologies of marasmus via the restricted intake protocol and incipient kwashiorkor via the low-protein $\operatorname{protocol}^{(2,3,12)}$.

\section{Experimental design}

Two experiments were performed. In the first experiment, ten animals were included in each dietary group and blood samples were taken at day 3 , representative of the early stages of weight $\operatorname{loss}^{(2)}$. In the second experiment, intended to be confirmatory of a previous report pertaining to the advanced stages of malnutrition ${ }^{(3)}$, sample sizes consisted of ten animals in the age-matched control group and eight animals in both malnourished groups, and blood was taken after $14 \mathrm{~d}$. Equal numbers of males and females were included in all dietary groups from both experiments.

\section{Blood sampling procedure}

Orbital plexus blood samples were collected under $\mathrm{CO}_{2}$ anaesthesia as described previously ${ }^{(3)}$. Platelet-poor plasma was collected and stored at $-80^{\circ} \mathrm{C}$ as described previously ${ }^{(3)}$.

\section{Plasma transforming growth factor- $\beta$ bioassay}

The assay was based on the reduction of the proliferative activity of Mv1Lu mink lung cells (ATCC CCL-64) exposed to TGF- $\beta$ and was performed as described in detail elsewhere $^{(3)}$. Recombinant human TGF- $\beta 1$ (BD Biosciences, San Jose, CA, USA; catalogue \#559119) was used to generate standard curves (average $R^{2} 0.98$ ), and only linear portions of the curves were used. The intra-assay CV averaged $4.6 \%$, and the detection limit was $46 \mathrm{pg} / \mathrm{ml}$. Each plasma sample was analysed in triplicate.

\section{Carcass composition}

Carcasses were stored at $-80^{\circ} \mathrm{C}$ to await analysis of $\mathrm{DM}$ and total lipid content as described previously ${ }^{(10)}$.

\section{Statistical analysis}

Statistical analyses were conducted using the SAS system (SAS Institute, Cary, NC, USA) for Windows (version 9.0), and a pre-determined upper limit of probability of $P \leq 0.05$ was applied for statistical significance. Data were subjected to a one-way ANOVA followed, if justified by Tukey's Studentised Range test. Datasets not exhibiting a normal distribution were transformed. Where transformation attempts were unsuccessful, data were subjected to the KruskalWallis test ( $\chi^{2}$ approximation) followed, if justified, by Wilcoxon two-sample testing.

\section{Results}

Distinct weight loss pathologies were elicited by the malnutrition protocols

Growth indices for the two experiments are shown in Table 1. Within each experiment, initial body weights did not differ among groups. Moreover, the age-matched control groups exhibited food intakes and carcass composition outcomes comparable to those reported previously for $\mathrm{C} 57 \mathrm{BL} / 6 \mathrm{~J}$

Table 1. Initial and final body weights, food intakes and carcass compositions

(Mean values with their standard errors)

\begin{tabular}{|c|c|c|c|c|}
\hline \multirow[b]{2}{*}{ Index } & \multicolumn{3}{|c|}{ Dietary group } & \multirow[b]{2}{*}{ SEM } \\
\hline & $\mathrm{C}$ & LP & $\mathrm{R}$ & \\
\hline \multicolumn{5}{|l|}{ Day 3} \\
\hline Initial body weight (g/mouse) & $7 \cdot 9$ & $8 \cdot 2$ & $8 \cdot 2$ & 0.09 \\
\hline Final body weight (g/mouse) & $9 \cdot 6^{\mathrm{a}}$ & $7 \cdot 4^{\mathrm{b}}$ & $6 \cdot 9^{\mathrm{b}}$ & 0.09 \\
\hline Food intake (g/mouse per d) & $2 \cdot 2^{\mathrm{a}}$ & $1 \cdot 6^{\mathrm{b}}$ & $1 \cdot 1^{\mathrm{c}}$ & 0.03 \\
\hline $\begin{array}{l}\text { Food intake }(\mathrm{g} / \mathrm{g} \text { body } \\
\text { weight per } \mathrm{d})^{*}\end{array}$ & $0 \cdot 17^{\mathrm{a}}$ & $0 \cdot 13^{b}$ & $0 \cdot 10^{c}$ & 0.001 \\
\hline $\begin{array}{l}\text { Carcass DM (g/100 g wet } \\
\text { weight) } \dagger\end{array}$ & $29 \cdot 5^{a}$ & $29 \cdot 0^{a}$ & $27 \cdot 8^{\mathrm{b}}$ & - \\
\hline $\begin{array}{l}\text { Carcass lipid (g/100 g wet } \\
\text { weight) }\end{array}$ & $8 \cdot 9^{a}$ & $6 \cdot 6^{\mathrm{b}}$ & $3 \cdot 9^{c}$ & 0.14 \\
\hline \multicolumn{5}{|l|}{ Day 14} \\
\hline Initial body weight (g/mouse)‡ & $8 \cdot 4$ & $8 \cdot 5$ & $8 \cdot 4$ & 0.006 \\
\hline Final body weight ( $\mathrm{g} /$ mouse $) \S$ & $18 \cdot 3^{a}$ & $6 \cdot 2^{\mathrm{b}}$ & $6 \cdot 4^{\mathrm{b}}$ & 0.01 \\
\hline Food intake (g/mouse per $d) \|$ & $2 \cdot 6^{\mathrm{a}}$ & $1 \cdot 2^{\mathrm{b}}$ & $0.9^{\mathrm{c}}$ & - \\
\hline $\begin{array}{l}\text { Food intake ( } g / g \text { body weight } \\
\text { per } d) \S\end{array}$ & $0 \cdot 15^{a}$ & $0 \cdot 10^{\mathrm{b}}$ & $0 \cdot 07^{c}$ & 0.03 \\
\hline $\begin{array}{l}\text { Carcass DM (g/100 g wet } \\
\text { weight) }\end{array}$ & $32 \cdot 0^{\mathrm{a}}$ & $29 \cdot 1^{b}$ & $27 \cdot 8^{b}$ & - \\
\hline $\begin{array}{l}\text { Carcass lipid ( } \mathrm{g} / 100 \mathrm{~g} \text { wet } \\
\text { weight) }\end{array}$ & $9 \cdot 6^{\mathrm{a}}$ & $4 \cdot 8^{b}$ & $2 \cdot 2^{c}$ & 0.17 \\
\hline
\end{tabular}

C, group that consumed ad libitum the complete diet; LP, group that consumed ad libitum an isoenergetic low-protein diet; $\mathrm{R}$, group that consumed the complete diet in restricted daily quantities.

a,b,c Mean values within a row with unlike superscript letters were significantly different $(P \leq 0.05)$ according to Tukey's Studentised Range test, unless a different statistical procedure is indicated.

* From ANOVA of squared-transformed data. Mean values are square roots of squared means.

†Kruskal-Wallis test of Wilcoxon rank sums that were as follows: C, 187; LP, 188; $\mathrm{R}, 90$.

‡From ANOVA of inverse-transformed data. Mean values are the inverse of the transformed means.

$\S$ From ANOVA of natural log-transformed data. Mean values are antilogs of log means.

|| Kruskal-Wallis test of Wilcoxon rank sums that were as follows: C, 215; LP, 98.5; $R$, 37.5.

ๆ Kruskal-Wallis test of Wilcoxon rank sums that were as follows: C, 202; LP, 83.5; R, 65.5 


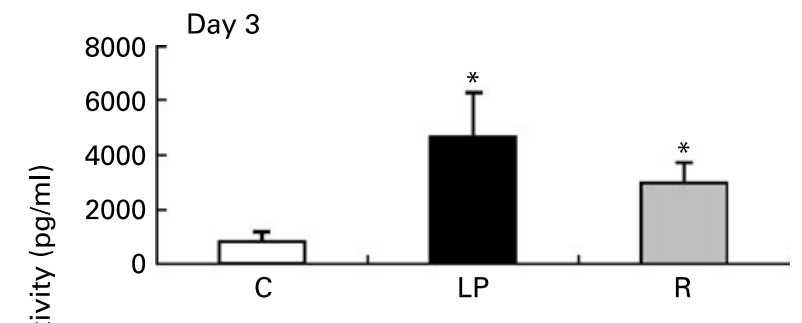

Fig. 1. Plasma transforming growth factor (TGF)- $\beta$ bioactivity. Weanling C57BL/6J mice, initially $19 \mathrm{~d}$ old, were fed ad libitum a complete purified diet (group C, age-matched controls), or the complete diet in restricted daily quantities (group R) or were given free access to an isoenergetic low-protein diet (group LP). Equal numbers of males and females contributed to samples sizes of ten in all dietary groups (upper panel, day 3), or to sample sizes of ten (group C) and eight in each malnourished group (lower panel, day 14). Bars represent mean values and the SEM is shown in each case. Within each experiment, data were analysed by one-way ANOVA. Day 3: means are antilogs of natural log-transformed means; diet $P=0.0004$, pooled $\mathrm{SEM}=0 \cdot 16$. Day 14: diet $P=0.0001$, pooled SEM $=339$. Bars marked with an asterisk $\left(^{*}\right)$ differ from their corresponding age-matched control group $(P \leq 0.05)$ according to Tukey's Studentised Range test.

weanlings consuming the complete purified diet ${ }^{(2,3,12)}$. At the end of each experiment, the body weights and food intakes of the malnourished groups were lower than their corresponding age-matched control group. Also, each malnourished group exhibited a lower carcass fat level than its corresponding age-matched control, and the restricted intake protocol induced a greater decrement in carcass fat, and hence in carcass energy, than the low-protein protocol. Overall, the loss of both fat and lean tissue produced by the two malnutrition protocols was comparable to the outcomes reported previously when inflammatory immune competence was shown to be depressed in the same experimental systems ${ }^{(10-12)}$.

\section{Plasma transforming growth factor- $\beta$ bioactivity}

Plasma TGF- $\beta$ bioactivities are shown in Fig. 1. Samples from all groups exhibited plasma bioactivities that exceeded the detection limit of the assay. Plasma TGF- $\beta$ bioactivities found in the age-matched control groups were consistent with concentrations reported previously in plasma samples from healthy adolescent and young adult mice ${ }^{(3,14)}$. In relation to the main objective of this investigation, plasma TGF- $\beta$ bioactivities were elevated in both malnourished groups after only $3 \mathrm{~d}$ of weight loss, and the high blood levels of this cytokine were sustained into the advanced stages of protein and energy deficit.

\section{Discussion}

This investigation reveals that the plasma concentration of TGF- $\beta$ rises early in response to acute pre-pubescent deficits of protein and energy, and demonstrates that the high levels of this anti-inflammatory cytokine are maintained into the advanced stages of weight loss. The findings pertaining to the later stages of malnutrition confirm previous reports ${ }^{(2,5)}$. This outcome was apparent in two metabolically distinct murine models that mimic the critical features of paediatric marasmus and incipient kwashiorkor ${ }^{(2,3,12)}$. Thus, a potently anti-inflammatory triad of soluble mediators, namely the glucocorticoids, IL-10 and TGF- $\beta$, emerges when this work is considered together with previous reports ${ }^{(2-5)}$ and provides a basis for understanding both initiation and maintenance of depressed inflammatory competence in acute pre-pubescent malnutrition. More broadly, this investigation provides new experimental underpinning for the concept ${ }^{(1)}$ that malnutrition-associated immune depression is part of a regulated pathophysiology, the antithesis of a biologically trivial disintegration of immunological capacities.

Attempts to achieve a biologically meaningful assessment of TGF- $\beta$ concentrations in blood and other tissue fluids are complicated by the existence of three mammalian isoforms of this protein mediator, designated $\beta 1-3,{ }^{(15)}$ and by the fact that much of the cytokine circulates in latent form ${ }^{(16)}$. Only the $\beta 1$ isoform is detectable in the blood of the healthy mouse or of mice subjected to the low-protein protocol used herein, whereas both $\beta 1$ and $\beta 2$ isomers are reported at high levels in the blood of mice subjected to our food intake restriction protocol ${ }^{(3)}$. It is important, therefore, that the three mammalian isoforms exhibit indistinguishable immunological influences, at least in vitro ${ }^{(3)}$, and equal biological activity in the bioassay used herein ${ }^{(15)}$. Moreover, TGF- $\beta$ immunoassays $^{(17)}$ and bioassays ${ }^{(5,17)}$ frequently include an initial activation step that releases the cytokine from its latent form, thereby inflating the measurement that is interpreted as biologically active TGF- $\beta$. However, this assay strategy was not used in the present investigation. To the extent that blood cytokine concentrations reflect extravascular levels ${ }^{(3,6)}$, therefore, the TGF- $\beta$ concentrations determined herein are directly relevant to the levels of biologically active cytokine that target cells would encounter in vivo.

Numerous possibilities merit investigation as contributors to high circulating levels of TGF- $\beta$ in acute malnutrition. In this connection, findings pertaining to the small intestinal epithelium and lamina propria of acutely malnourished infants and children lend no support to the possibility of an increase in the rate of cytokine synthesis ${ }^{(18)}$. However, a much more extensive cellular survey is needed as virtually all cells can produce TGF- $\beta^{(16)}$. Likewise, reduced turnover must be considered in parallel with findings reported for other circulating proteins of acutely malnourished children, e.g. IgG class $\operatorname{Ig}^{(19)}$ and some acute-phase proteins ${ }^{(20,21)}$. An intriguing possibility pertains to the extracellular matrix, which appears to serve as a reservoir for TGF- $\beta^{(16,22)}$. Proteolytic degradation of the extracellular matrix liberates TGF- $\beta$ from its latent complex, thereby coupling matrix turnover with the activation of TGF- $\beta^{(22)}$. Thus, by exaggerating a normal physiological phenomenon, the catabolic metabolism of acute malnutrition may support a rapid and sustained elevation in blood and tissue fluid concentrations of a potent anti-inflammatory cytokine in its active form. In this connection, protein- and energy-deprived rats exhibit decreased soluble and insoluble collagen skin content in comparison to healthy controls ${ }^{(23)}$. 
The glucocorticoids, IL-10 and TGF- $\beta$ comprise a network of partially redundant anti-inflammatory hormonal mediators effective against diverse innate and adaptive immune defence elements and widely regarded as the backbone of peripheral tolerance ${ }^{(7-9,24,25)}$. The present investigation completes the picture with respect to this potent network in acute prepubescent malnutrition. It is now apparent, from this investigation and other reports ${ }^{(2-4)}$, that the three component mediators rise early and are sustained in unison throughout the progression of weight loss. In turn, this points to the recent proposition of a coordinated and purposeful immune regulation in which the inflammatory form of competence is supplanted by an anti-inflammatory form that is tolerant of the self-antigens catabolically released in quantity during wasting malnutrition ${ }^{(1,3)}$. This tolerance-centred model emphasises the adaptive benefit of a reduced risk of autoimmune disease while acknowledging the cost in terms of susceptibility to infectious disease. Other anti-inflammatory mediators, e.g. IL-35 ${ }^{(24)}$, can be accommodated within the tolerance model, and their participation can be anticipated in the non-inflammatory immune competence of acute prepubescent malnutrition.

\section{Acknowledgements}

The work reported herein was supported by a Postgraduate Scholarship and a Discovery Grant awarded, respectively, to J. M. M. and B. W. by the Natural Sciences and Engineering Research Council of Canada. The study idea originated with J. M. M. The study was designed jointly by J. M. M. and B. W., and the experimental work was done by J. M. M. Both J. M. M. and B. W. contributed to the interpretation of results and the preparation of the manuscript. Technical assistance provided by Ms Rinu Pazhekattu in connection with carcass analyses is gratefully acknowledged. The authors have no conflicts of interest to declare.

\section{References}

1. Woodward B (2004) Depressed adaptive immune competence in acute protein-energy malnutrition: a regulated pathophysiology controlled by endocrine hormones and cytokines. In Nutrition and Immunology in the 21st Century, pp. 23-38 [RK Chandra, editor]. Toronto: TSAR Health.

2. Monk JM, Makinen K, Shrum B, et al. (2006) Blood corticosterone concentration reaches critical illness levels early during acute malnutrition in the weanling mouse. Exp Biol Med 231, 264-268.

3. Hillyer L, Dao B, Niemiec P, et al. (2006) Elevated bioactivity of the tolerogenic cytokines, interleukin-10 and transforming growth factor- $\beta$, in the blood of acutely malnourished weanling mice. Exp Biol Med 231, 1439-1447.

4. Monk JM \& Woodward B (2009) Elevated blood interleukin-10 levels and undiminished systemic interleukin-10 production rate prevail throughout acute protein-energy malnutrition in the weanling mouse. Cytokine 47, 126-131.

5. Dai G \& McMurray DN (1998) Altered cytokine production and impaired antimycobacterial immunity in protein-malnourished guinea pigs. Infect Immun 66, 3562-3568.

6. Bienvenu JAD, Monneret G, Gutowski MC, et al. (1998) Cytokine assays in human sera and tissues. Toxicology 129, 55-61.
7. Li MO, Wan YY, Sanjabi S, et al. (2006) Transforming growth factor- $\beta$ regulation of immune responses. Annu Rev Immunol 24, 99-146.

8. Zhang L, Yi H, Xia X-P, et al. (2006) Transforming growth factor-beta: an important role in $\mathrm{CD} 4^{+} \mathrm{CD} 25^{+}$regulatory $\mathrm{T}$ cells and immune tolerance. Autoimmunity 39, 269-276.

9. Li MO \& Flavell RA (2008) Contextual regulation of inflammation: a duet by transforming growth factor- $\beta$ and interleukin-10. Immunity 28, 468-476.

10. Woods JW \& Woodward BD (1991) Enhancement of primary systemic acquired immunity by exogenous triiodothyronine in wasted, protein-energy malnourished weanling mice. $J$ Nutr 121, $1425-1432$.

11. Woodward BD, Woods JW \& Crouch DA (1992) Direct evidence that acquired cell-mediated immunity is less resistant than is primary thymus-dependent humoral immunity to the depressive influence of wasting protein-energy malnutrition in weanling mice. Am J Clin Nutr 55, 1180-1185.

12. Ha C-L, Wong SS-L, Gray MM, et al. (2001) Overabundance of $\mathrm{CD}_{45 \mathrm{RA}^{+}}$(quiescent-phenotype) cells within the involuted $\mathrm{CD} 4^{+} \mathrm{T}$-cell population follows initiation of immune depression in energy-deficient weanling mice and reflects involution exclusive to the CD45RA ${ }^{-}$subset. J Nutr 131, 1812-1818.

13. Filteau SM \& Woodward B (1987) Influence of severe protein deficiency and of severe food intake restriction on serum levels of thyroid hormones in the weanling mouse. Nut Res 7, 101-107.

14. Tanaka M, Miyazaki H, Takeda Y, et al. (1993) Detection of serum cytokine levels in experimental cancer cachexia of colon 26 adenocarcinoma-bearing mice. Cancer Lett 72, $65-70$.

15. Graycar JL, Miller DA, Arrick BA, et al. (1989) Human transforming growth factor- $\beta 3$ : recombinant expression, purification, and biological activities in comparison with transforming growth factors- $\beta 1$ and $-\beta 2$. Mol Endocrinol 3, 1977-1986.

16. Taylor AW (2009) Review of the activation of TGF- $\beta$ in immunity. J Leukoc Biol 85, 29-33.

17. Kanzler S, Baumann M, Schirmacher P, et al. (2001) Prediction of progressive liver fibrosis in hepatitis $\mathrm{C}$ infection by serum and tissue levels of transforming growth factor- $\beta$. J Viral Hepat 8, 430-437.

18. Campbell DI, Murch SH, Elia M, et al. (2003) Chronic T cellmediated enteropathy in rural west African children: relationship with nutritional status and small bowel function. Pediatr Res 54, 306-311.

19. Chandra RK \& Newberne PM (1977) Nutrition, Immunity, and Infection Mechanisms of Interaction. New York: Plenum Press.

20. Morlese JF, Forrester T, Badaloo A, et al. (1996) Albumin kinetics in edematous and nonedematous protein-energy malnourished children. Am J Clin Nutr 64, 952-959.

21. Morlese JF, Forrester T \& Jahoor F (1998) Acute-phase protein response to infection in severe malnutrition. Am J Physiol 275, E112-E117.

22. Annes JP, Munger JS \& Rifkin DB (2003) Making sense of latent TGF- $\beta$ activation. J Cell Sci 116, 217-224.

23. Anasuya A \& Narasing Rao BS (1970) Relationship between body collagen and urinary hydroxyproline excretion in young rats fed on a low-protein or low-calorie diet. Br J Nutr 24, 97-107.

24. Vignali DAA, Collison LW \& Workman CJ (2008) How regulatory T cells work. Nat Rev Immunol 8, 523-531.

25. Karagiannidis C, Akdis M, Holopainen P, et al. (2004) Glucocorticoids upregulate FOXP3 expression and regulatory $\mathrm{T}$ cells in asthma. J Allergy Clin Immunol 114, 1425-1433. 